\title{
Live Case Analysis: Pedagogical Problems And Prospects In Management Education
}

Kevin J. Roth, Clarion University of Pennsylvania, USA

Chad Smith, Clarion University of Pennsylvania, USA

\begin{abstract}
The selection of an appropriate and effective pedagogy has been a central theme in management education for decades. There currently exists a wide range of pedagogical options designed to match course content with the most appropriate technique(s) for effective learning outcomes. Most recently, a variety of experiential learning methods have been employed to provide students with real-life experiences and applications in the overall class design. Live case analysis is typically identified as one of a series of options within the domain of experiential learning methods. This paper examines the live case approach as a tool for achieving desired outcomes in management education. Perspectives are offered from multiple stakeholder groups that highlight both the challenges and prospects in the use of this method of teaching. Results demonstrate the usefulness of the live case approach for achieving assessment objectives and measuring important program outcomes.
\end{abstract}

Keywords: experiential learning, case analysis, program assessment

\section{INTRODUCTION}

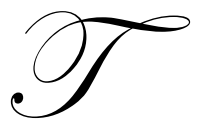

he traditional case method has served as a longstanding pedagogical approach employed across a wide range of disciplines. Normally described as one of a number of experiential approaches, the case method is typically seen as extending and synthesizing course content by providing specific application to real organizational problems and issues. This approach has an extensive literature base regarding overall use and effectiveness. Historically, case analysis as a pedagogical approach in business education largely stems from early work at Harvard University.

This paper is designed to extend the traditional case method by examining the use of a pedagogical approach where direct interaction with a "live" organization is employed. In essence, live cases are fully incorporated into both course content and process. The live case approach typically incorporates extended analysis and problem solving through mutual agreement by the student/faculty member and the client/organization. Couched in the broader field of experiential learning, the application of the live case approach for this research rests on providing an overall "strategic" assessment of the organization along with a pre-conditioned narrowing to issue identification and specific strategic direction.

This research is based on the use of the live case method over eight years in an MBA capstone course in strategic management. Input has been provided from multiple client/organizations during this time frame. Perspectives are offered from student consultants, organization leadership/business owner(s), faculty coordinator/facilitator and the host institution. The study is positioned to extend the knowledge base of appropriate pedagogy and highlight the corresponding problems and prospects associated with the use of this technique in management education.

\section{TRADITIONAL CASE METHOD}

There are a variety of teaching methods that effectively convey information and understanding to students (Martin, 1998). The traditional case method of teaching traces its history to the early development efforts and use at 
Harvard University. As an early form of the experiential method, historical cases have presented effective opportunities for learning and application. According to a historical perspective provided by Gras and Larson (1939), cases are seen as providing a background and perspective for judgement on business direction along with an appreciation of continuous change and necessary organizational adaptation. Regarding the case approach to teaching, Bocker (1987, p. 64) states that:

"universities and other training institutions use real-world case studies as pedagogical tools to bring problems and approaches from the managerial world to the classroom. Cases provide material with which one can practice decision making: therefore, cases may be classified as tools that allow one to simulate managing a company. Case teaching is said to better motivate students and to transmit information to students more effectively than lecture teaching. Some use cases to demonstrate real-world practices and to liven up their teaching, and others use cases as the foundation of an integrated inductively driven teaching process."

Research on the application of the case analysis method is widespread. Because of the "real world" orientation, cases have been widely accepted in business and management education (Christenson and Hanson, 1987). For example, Peterson and Govindarajulu (2003) provide a useful appraisal of historical cases and their use as a teaching tool. The authors offer an outline for use in management. Additional research describes the advantages and disadvantages of the case study method along with overall expectations, use, effectiveness and potential pitfalls (Smith 1987, Osigweh 1987, Richardson 1994, Greenawalt 1994, Cinneide 1997, Wolfe 1998, Bruner et al 1999, Booth 2000, Gomes and Knowles 2000). In terms of administration, Dooley and Skinner (1977) identify the various roles played by the faculty member including facilitator, coach, quarterback and demonstrator. Each role highlights a different approach for moving students through the learning process. Jennings $(1996,1997)$ and Siciliano and McAleer (1997) extend this work by offering insights to the specific use of the case method in the teaching of strategic management which is the primary focus of this research.

The limitations of the traditional case method in general are described by Argyris (1980). Argyris expresses concern regarding the inability of the case method to question the underlying values or policies of leadership thus impacting new learning. In response, Berger (1983) questions the Argyris methodology in defence of the case method in corporate education. Additional limitations of the traditional case method and a purely decision-focused case approach are presented by Andrews and Noel (1986), Lundberg et al (2001), and Lincoln (2006).

\section{EXPERIENTIAL LEARNING}

Various authors suggest that students today are "active learners" and therefore need a new learning environment that is more collaborative, experiential, team or group based and as self-paced as possible (Close et al 2005, Oblinger 2005, Twenge 2006, Matulich et al 2008). Business education in particular is identified as transitioning from a "professor-centered" orientation to a "process-based" approach that emphasizes the need for higher levels of student interaction (Bigelow et al 1998, Bobbitt et al 2000, Schlee and Van Duzer 2007).

Experiential learning as a process-based approach has continued to develop as a popular teaching method where student involvement and the application of real-life situations to concepts and theories are emphasized (Bobbitt et al 2000, Razzouk et al 2003, Schlee and Van Duzer 2007). In order to overcome limitations of the traditional case approach, Singh and Eischen (2007) report that executives advocate experiential, on-the-job learning and understanding of context in response to weaknesses in creative problem solving, decisions making and innovative thinking.

With specific relation to the content of this research paper, Parente et al (2006) offer support for the use of experiential oriented learning approaches to achieve effective acquisition of specific strategic management skills. Important dimensions identified include such soft skills as people skills, group skills and leadership skills that are found to lead to more strategic skills and abilities. The results accent the growing emphasis on the development of "soft skills" in management education. 


\section{LIVE CASE APPROACH}

A more recent variant of experiential learning and the case method is the use of a live case approach to teaching. This pedagogy often incorporates a "students as consultants" perspective and has been presented as an alternative for service learning (Kenworthy U'Ren, 1999). Simpkins (2001, p.1) describes live cases as a "current problem or issue that a company is investigating where the company provides information regarding the problem/issue seeking input to assist in management decisions." This approach examines the effectiveness of the live case method applied to a single firm in a graduate level finance course. The results provide a useful conceptual base for further examining their use and effectiveness.

Additional research suggests that using real-world experiences through organizational field projects provide measurable benefits to students, the client organization, and the educational institution involved (Barkman 1998, Richardson and Ginter 1998, LeClaire and Stottinger 1999, Ahire 2001, Simpkins 2001, Kennedy et al 2001, Lincoln 2006). Such studies have included a wide range of application to the various functional areas of business including finance, accounting, information systems, marketing, operations and strategic planning.

According to Matulich et al (2008, p.4), "live cases bring a sense of accomplishment to the student at the same time they are applying concepts to a client that needs help." In a management development context, the live case method is also seen as an increasingly influential means of broadening the thinking of middle managers (Urban and Keys, 1994). When considering general acceptance and broad appeal, it should be noted that the live case method is consistent with the recent Association to Advance Collegiate Schools of Business (AACSB) "action learning practices" (AACSB 2005, 2006) and articulation of the major features of the ideal MBA curriculum (Navarro, 2008).

\section{RESEARCH PROCESS AND CONTENT ISSUES}

The information base for this research is derived from a strategic management and business policy graduate course that is offered each spring. The live case constitutes a semester-long project where small groups (3-4 students) address strategic issues facing a client/organization. A wide range of organizations have been incorporated in terms of size, economic sector, and profit/non profit orientation. Industry examples include brewing, aggregates, mining equipment, technology, powdered metals, education, economic development, real estate, financial services and construction. The specific issues that have been addressed range from a functional level focus to line of business and broader corporate level strategy. Approximately thirty organizations have been included over an eight-year time period from 2001 through 2008.

The live case process is administered after several weeks of examination of the content material of strategic management. In terms of course content, students apply a strategic management perspective employing both external environment and organizational analysis through the use of a structured strategic audit framework. Analysis extends to mission review and development as well as organizational governance. Students are moved towards problem/issue identification resulting in specific strategic options and direction presented to the organization. A strategic flow diagram that incorporates strategic outcomes and corresponding measurements is also presented to assist the organization with future planning efforts.

\section{CHALLENGES AND PROSPECTS}

The use of a live case teaching method offers a number of challenges along with prospects for continued use. In this section of the paper, perspectives on these challenges and opportunities are offered from relevant stakeholders including students, the client/organization, faculty member/facilitator and the host institution. Stakeholder perspectives are based on information gathered through formal and informal input throughout the live case process. In addition, stakeholders (students and clients) were asked to provide feedback upon completion of an individual case project. 


\section{Student Perspective}

The student perspective is based on information collected across multiple years and throughout the administration of each live case process. The areas of input that have been collected address the effectiveness in the application of the process itself, content knowledge gained, the ability to apply content knowledge, skills derived based on live interaction with the organization and organization leadership and the individual and group skill sets enhanced throughout the process.

Students consistently commented favourably regarding their enhanced understanding of the course content and their ability to effectively apply these concepts to a live company. Responses included specific reference to seeing "core concepts" in action with the ability to apply content theories, models and tools. Students identified the direct interaction with organization leadership as an important and worthwhile experience. This interaction offered important insights into governance issues, political and behavioural processes along with exposure to core values and ethical standards important to organizational decision making.

For many students, the ability to integrate the various organization resource areas was identified as an important learning outcome. Both the content and the process of strategic management seemed to lend itself naturally to such integration. The specific skill enhancement areas highlighted by students included refinements to the areas of effective communication, time management, interpersonal relations, decision making, problem solving, conflict resolution, and team interaction. These skill sets are consistent with outcomes and expectations normally held and measured by business programs and accrediting agencies.

While many positive outcomes were identified, several important challenges continue to impact overall effectiveness. Those that were highlighted include limited or insufficient client commitment and availability, team schedule coordination, traditional team based issues (ex: individual member commitment and contribution) and the limitations of a one-semester time frame. These challenges appeared consistently across organization type and scope.

\section{Client/Organization Perspective}

The client/organization perspective is based on both formal input requested of the client along with informal discussions held during and after project submission. It was requested that each organization provide an evaluation of the process as well as recommendations for future administration in a letter format. Areas of primary consideration included an examination of tangible organization results vs. student learning experience, time constraints on personnel, strategy implementation and control issues and the confidentiality of information.

Tangible results to the organization appeared in several forms. In many cases, this included a confirmation of what was already known but questioned by the organization. An initial analysis typically resulted in providing a descriptive perspective of the organization. This was found to be both useful and practical by the organization. These results many times confirmed pre-existing perceptions held by the organization. This provided useful input in the determination of eventual strategic direction and needed organizational change efforts.

The most rewarding results centered on the potential "new or improved" idea, vision, or strategic direction underutilized or in some cases overlooked by the organization. Based on client comments provided, this is consistent with the majority of organizations in terms of the desired outcome in this type of analysis. Recommendations were sometimes limited due to factors including time constraints, access to data and information, enthusiasm of those involved in the process and organization political and behavioral processes that existed.

Organization members perceived "learning" and the supporting knowledge base created as extending both ways while enhanced by all those involved in the process. "Organizational learning" derived from this type of experience was achieved through a descriptive process of detailing what they already new and understood. By extending this description to insights and specific direction proposed by the students, the clients identified the process as providing a certain level of reassurance and a greater understanding. This was particularly noticeable in 
the analysis of external variables influencing organization change and ensuing possibilities in strategic direction. Many clients felt a heightened awareness was created of an overlooked resource area or strategy.

An additional outcome specified by clients focused on unseen opportunities that were exposed based on the interaction with outside students. This resulted in healthy discussions and insights to potential new/future employees and a glimpse into course content being taught from the university providing the service. The organizations uniformly felt they were providing a beneficial learning experience for the students involved.

In the majority of cases, organizational members felt the students derived distinctive benefits from the experience. It was stated that direct exposure to organizational processes and procedures provided students a deeper understanding and helped to extend theoretical models and application to an applied setting. In addition, real situations presented themselves during the course of the case analysis. Such situations included working with conflicting personalities, establishing effective communication flow, and the development of the skills necessary to deal with pressures of getting a quality project done on time.

Time constraints of organizational members surfaced as a significant barrier in the live case process. Students were required to gathering accurate information in a short period of time from a range of organizational members. The students also had to conform to deadlines established by the organization during different stages of the analysis. These time constraints on personnel appeared to be a significant deterrent for organizations from participating in a live case analysis.

In order to achieve effective outcomes, it was necessary for each organization to provide the students with access to the appropriate person(s). In a majority of cases, this included individuals in upper levels of management. This is where adequate organizational knowledge and the necessary access to information was found or at least initiated. In many cases the organization allocated the time of personnel representing various departments at some point during the data gathering stage. Time constraints were also identified as impacting the overall depth of analysis. Results suggest that this is a critical area that must be collaboratively addressed prior to any project consultation agreement.

Beyond final findings and presentation of the live case analysis, implementation and control were identified as a key area of concern. This consistently emerged as a difficult element in the coordination of the live case method. Organizations were often left with promising strategic direction and guidance but inadequate personnel and/or resources to implement suggestions. In many situations, this occurred as a result of an organization already "running lean." In many cases, additional research or questions emerged that had to be addressed before implementation could take place. The reality is that many organizations selected only the findings which were easy to implement with the expectation of revisiting additional findings at a later time.

The use of proprietary or confidential information also emerged as a concern for organizations involved in the live case process. (See Schlee and Van Duzer, 2007 for an overview of the role of confidential information in the case approach). Managers and owners were at times reluctant in sharing vital information that was necessary. These fears extended to the potential use of information to initiate a similar business, leaks to competitors, and a heightened insecurity by employees. In particular, companies that were privately held identified confidentiality as a potential barrier to the process. It was necessary to spend time articulating the necessity of pertinent information to the outcomes of the process. For several organizations, policy statements were in place that included language regarding a required confidentiality statement. In these situations, this was seen by the organization as a natural and necessary process in the protection of the organizational information. This also provided a learning experience for students dealing with confidentiality contracts that many organizations used upon hiring a new employee.

\section{Faculty Coordinator Perspective}

While this study advocates the use of the live case method, it is recognized as one of a number of pedagogical approaches appropriate for effective management education. In the administration of the live case process, the primary faculty challenges that consistently surfaced included organizational selection/timing, effective student group formation, specific faculty role, and organizational problem/issue identification. 
Organization selection was found to be a critical element to the success of a live case program. Physical location, organization interests and needs, level of commitment, and availability of key personnel were found to influence the overall effectiveness. Attention must be given early in the process in order to create open and realistic goals and a framework for communication. The range of potential organizational sources are widespread and can include Small Business Development Centers, Chambers of Business and Industry, Economic Development Agencies, Planning Commissions, related government agencies, and non-profits. Timing also frequently emerged as an issue in terms of matching organizational needs with course and student availability.

Team/group member selection can be problematic in any activity where individuals must undertake a specific task as a team and offer unified recommendations. While students frequently struggle though issues resulting from group interactions, post process comments are uniformly favourable regarding the benefits derived. Team assignment options have included self-selection, interest area matching, professional background balance and random assignment. Self selection has provided the most consistent positive results over time.

While the faculty member can serve in many roles in the live case process, the facilitator role appears to offer the most rewarding experience to all parties. In the facilitator role, the faculty member serves as a go-between providing necessary direction and support. In this role, the faculty member does not serve as an additional team consultant. It was found that some flexibility on faculty member role was necessary, however, with adjustments made depending on team and organizational circumstances.

Some difficulties were evident in discussions with the client regarding expectations in both the nature and scope of the project itself. In several cases, organizations held expectations well beyond the scope of available time and resources. It became critical to reach early consensus and definition regarding the scope of the project as well as outcomes to be derived. As an outcome, it was expected that students gain insights and experience in both problem/issue identification and problem solving. The most effective cases were those that found a balance between the needs of organization leadership and the overall learning experience of team members.

\section{ASSESSMENT AND OUTCOMES}

A vital component in this pedagogy is that it offers the ability to assess and measure outcomes and their consistency with the mission, goals and objectives of the academic program. With assessment continuing to emerge as a critical factor in program review, measurable outcomes are becoming increasingly important. Goals included for measurement as outcomes of the live case process have included skill enhancement in strategic integration, interpersonal communication, oral communication, written communication, critical thinking, collaboration, team effectiveness, problem solving and decision making. A host of rubrics have been developed to facilitate the measurement process for these skill areas. It is important to recognize that measurement of these various outcomes needs to move beyond the internal evaluations provided by faculty member. Strategies used in this process have extended to individual student portfolio development, external advisory board review and input, client reviews and input, and external faculty review and input. These assessments have provided considerable input for continuous program improvement.

There are also clear opportunities to achieve institutional and host community benefits from the live case process. Over time, organizational interactions with students resulted in both internships and longer term employment opportunities. Other tangible benefits and outcomes were found with measures of university mission consistency, overall external relations, community engagement opportunities, institutional development efforts, program input and evaluation and outreach/economic development impacts.

\section{CONCLUSIONS}

This study suggests that significant outcomes with measurable results can be achieved through the use of live cases. In order to be effective, stakeholders must strive for a balance between the organization contributions and the learning experience achieved by students. It is important to find the "fit" and appropriate process within the course/program offering. The approach must also be tailored to fit the course delivery mode (traditional, web-based, hybrid). Primary attention must be paid to the issues of group formation, definition of objectives, organizational 
commitment, confidentiality, problem/issue identification, the appropriate measurement of program goals and the measurement of outcomes.

Future recommendations for enhancing this research are to consider the inclusion of a second live case course offering in the study sample, the development of an inventory of organizations for follow-up projects (implementation concerns), and improved follow-up with students regarding post-graduation impact. It is believed that the primary contribution of this research lies in extending the current understanding of both the use and application of live cases as an important and useful pedagogical option in management education.

\section{AUTHOR INFORMATION}

Dr. Kevin J. Roth is a Professor of Administrative Science at Clarion University of Pennsylvania. His teaching and research interests include strategic management, entrepreneurship and community planning.

Dr. Chad Smith is an Associate Professor of Administrative Science at Clarion University. His teaching and research interests include information systems, quality management and project management.

\section{REFERENCES}

1. Ahire, S.L. (2001) "Linking Operations Management Students Directly to the Real World," Interfaces, 31 (5), 104-120.

2. Andrews, E.S. and J.L. Noel (1986), “Adding Life to the Case Study Method, Training and Development Journal, 40 (2), 28-29.

3. Association to Advance Collegiate Schools of Business (AACSB) International (2005), Eligibility Standards for Business Accreditation, St. Louis MO; AACSB International.

4. Association to Advance Collegiate Schools of Business (AACSB) International (2006), Eligibility Standards for Business Accreditation, St. Louis MO; AACSB International.

5. Argyris, C. (1980) "Some Limitations of the Case Method: Experiences in Management Development Program," Academy of Management Review, 38, 502-528.

6. Barkman, A. (1998) "The Use of Live Cases in the Accounting Information Systems Course," Journal of Accounting Education, 16, 517-524.

7. Berger, M. (1983) "In Defense of the Case Method: A Reply to Argyris," Academy of Management Review, 8, 329-333.

8. Bigelow, J.D., J. Selzer, W. Buskirk, J. Hall, S. Schor, J. Garcia and K. Keleman (1998), "Management Skills in Action: Four Teaching Models," Journal of Management Education, 23 (February), 355-376.

9. Bobbitt, M.L., Inks, S.A., Kemp, K.J. \& Mayo, D.T. (2000) "Integrating Marketing Courses to Enhance Team-Based Experiential Learning," Journal of Marketing Education, 22 (April), 15-24.

10. Bocker, F. (1987), "Is Case Teaching More Effective Than Lecture Teaching in Business Administration? An Exploratory Analysis," Interfaces, 17, 64-71.

11. Booth, C., S. Bowie, J. Jordan, and A. Ripkin (2000) "The Use of the Case Method in Large and Diverse Undergraduate Programmes: Problems and Issues," The International Journal of Management Education, 1 (1), 62-75

12. Bruner, R.F., B.E. Gup, B.H. Nunnally, and C. Laurence (1999), "Teaching with Cases to Graduate and Undergraduate Students," Financial Practice and Education, 9 (Fall/Winter), 138-146.

13. Christensen, C.R. and A.J. Hanson (1987), Teaching and the Case Method, Boston: Harvard Business School Press.

14. Cinneide, B. O. (1997), "The Role and Effectiveness of Case Studies: Student Performance in Case Study vs. 'Theory' Examinations," Journal of European Industrial Training, 21 (1), 3-13.

15. Close, A.G., Dixit, A., Malhotra, N.K (2005), "Chalkboards to Cybercourses: The Internet and Marketing Education," Marketing Education Review, 15 (Spring), 81-94.

16. Dooley, A.R. and Skinner, W. (1977), "Casing Casemethod Methods," Academy of Management Review, 2 (2), 277-288.

17. Gomes, R. and P.A. Knowles (2000), “A Trust-Building Strategy to Reduce Adversarial Tension and Increase Learning in Case Pedagogy," Marketing Education Review, 10 (2) 49-58. 
18. Gras, N.S.B. and Larson, H.M. (1939), Casebook in American Business History, New York: Appleton-CenturyCrofts.

19. Greenawalt, M.B. (1994), "Student Written Case Studies: The Benefits to the Internal Audit Curriculum," Managerial Auditing Journal, 9 (2), 3-8.

20. Jennings, D. (1996), "Strategic Management and the Case Method," Journal of Management Development, 15 (9), 4-13.

21. Jennings, D. (1997), "Researching and Writing Strategic Management Cases: A Systems View," Management Decision, 35 (1/2), 100-105.

22. Kennedy, E.J., 1. Lawton and E. Walker (2001), "The Case for Using Live Cases: Shifting the Paradigm in Marketing Education," Journal of Marketing Education, 23 (August), 145-151.

23. Kenworthy-U'Ren, A. (1999), "Management Students as Consultants: An Alternative Perspective on the ServiceLearning Call to Action," Journal of Management Inquiry, 379-387. 8 (4),

24. LeClaire, D.T. and B. Stottinger (1999), "Using an Intensive Living Case in Graduate Marketing Courses: Experiences from an International Project," Marketing Education Review, 9 (3), 31-40.

25. Lincoln, D.J. (2006) "Student Authored Cases: Combining Benefits of Traditional and Live Case Methods of Instruction," Marketing Education Review, 16 (1), 1-7.

26. Lundberg, C.C., Rainsford, P., Shay, J.P. and Young, C.A. (2001) "Case Writing Reconsidered," Journal of Management Education, 25 (4), 450-464.

27. Martin, V. (1998), "Developing Managers in the 1990's Public Services: New Requirements in Public Service Management Development," Total Quality Management, 9 (3), 279-288.

28. Matulich, E., Papp, R. and Haytko, D. (2008), "Continuous Improvement through Teaching Innovations: A Requirement for Today's Learners," Marketing Education Review, 18 (1), 1-7.

29. Navarro, P. (2008), "The MBA Core Curricula of Top-Ranked U.S. Business Schools: A Study in Failure," Academy of Management Learning and Education, 7 (1), 108-123.

30. Oblinger, D. (2003), "Boomers, Gen-Xers and Milllennials: Understanding the New Students," http://www.educause.edu/ir/library/pdf/erm0342.pdf.

31. Osigweh, C.A.B. (1989) "Casing the Case Approach in Management Development," The Journal of Management Development, 8 (2), 41-58.

32. Parente, D., J. Stephan and R.C. Brown (2006), "Understanding the Big Picture: An Explanatory Model of Strategic Management Skills Acquisition," Academy of Management Proceedings, C1-C6.

33. Peterson, R.T. and L.G. Govindarajulu (2003) "Historical Cases as Teaching Tools in Management Courses - An Appraisal," Journal of Education for Business, (January/February), 170-173.

34. Razzouk, N.Y., V. Seitz and E. Rizkallah (2003), "Learning by Doing: Using Experiential Projects in the Undergraduate Marketing Course," Marketing Education Review, 13 (2), 35-41

35. Richardson, B. (1994) "Towards a Comprehensive View of the Case Method in Management Development," 26 (9), 3-10.

36. Richardson, W.D. and P.M. Ginter (1998) "Using Living Cases to Teach the Strategic Planning Process," Journal of Education for Business, 73 (5), 269-274.

37. Ross, J. and L. Wright (2000) "Participant-Created Case Studies in Professional Training," Journal of Workplace Learning: Employee Counseling Today, 12, 23-28.

38. Schlee, R.P. and Van Duzer, J.B. (2007), "An Examination of Alternative Approaches to the Treatment of Confidential Information in Live Case Projects," Marketing Education Review, 17 (2), 71-82.

39. Siciliano, J. and G.M. McAleer (1997), "Increasing Student Participation in Case Discussions: Using the MICA Method in Strategic Management Courses," Journal of Management Education, 21, 209-220.

40. Simpkins, B.J. (2001) "An Innovative Approach to Teaching Finance: Using Live Case in the Case Course," Oklahoma State University Working Paper.

41. Singh, N. and K. Eischen (2007), "Lost, Dysfuctional or Evolving? A View of Business Schools from Silicon Valley," IIMB Management Review, September, 329-344.

42. Smith, G. (1987) "The Use and Effectiveness of the Case Study Method in Management Education," Management Education and Development, 18, 51-61.

43. Twenge, J.M. (2006), Generation Me: Why Today's Young Americans Are More Confident, Assertive, Entitledand More Miserable Than Ever Before, Free Press.

44. Urban, T. and J.B. Keys (1994), "The Live Case Method of Creating the Learning Organization," Journal of Management Development, 13 (8), 44-50.

45. Wolfe, J. (1998), "New Developments in the Use of Cases for Learning," Journal of Workplace Learning, 10 (6/7), 320-323. 